\title{
Efficacy and safety of trastuzumab as maintenance or palliative therapy in advanced HER2-positive gastric cancer
}

\author{
Xiaomin Fu, ${ }^{1}, *$ Yong \\ Zhang, ${ }^{1, *}$ Jing Yang, ${ }^{2}$ \\ Yalong Qi,' Yue Ming,' \\ Miaomiao Sun, ${ }^{3}$ Yiman \\ Shang,' Yonghao Yang,' \\ Xiaoyan Zhu, ${ }^{4}$ Quanli Gao' \\ 'Department of Biology and \\ Immunotherapy, Affiliated Cancer \\ Hospital of Zhengzhou University \\ and Henan Cancer Hospital, \\ Zhengzhou, People's Republic of \\ China; ${ }^{2}$ Department of Pharmacy, The \\ First Affiliated Hospital of Zhengzhou \\ University, Zhengzhou, People's \\ Republic of China; ${ }^{3}$ Department of \\ Pathology, Affiliated Cancer Hospital \\ of Zhengzhou University and Henan \\ Cancer Hospital, Zhengzhou, People's \\ Republic of China; ${ }^{4}$ Department of \\ Histology and Embryology, College of \\ Basic Medicine, Zhengzhou University, \\ Zhengzhou, People's Republic \\ of China \\ *These authors contributed equally \\ to this work
}

Correspondence: Quanli Gao Department of Biology and Immunotherapy, Affiliated Cancer Hospital of Zhengzhou University and Henan Cancer Hospital, 127 Dong Ming Road, Jinshui, Zhengzhou 450003, People's Republic of China Email gaoquanli I@aliyun.com

Xiaoyan Zhu

Department of Histology and Embryology, College of Basic Medicine, Zhengzhou University, 100 Kexue Road, Zhengzhou 450052, People's Republic of China

Email zhxy@zzu.edu.cn
This article was published in the following Dove Press journal: OncoTargets and Therapy

Background: Human epidermal growth factor receptor 2 (HER2)-positive gastric cancer (GC) is a unique subtype of this disease. Few studies focus on the feasibility of trastuzumab as maintenance or palliative therapy for patients with HER2-positive advanced GC.

Patients and methods: We retrospectively analyzed the data of 11 patients, evaluated the efficacy and safety of trastuzumab, and attempted to investigate the prognostic factors for trastuzumab treatment. Among the 11 patients, one achieved partial response (PR), six achieved stable disease (SD), and four were evaluated as progressive disease (PD).

Results: The overall response rate (ORR) was $9.10 \%$, and the disease control rate (DCR) was $63.64 \%$. The median overall survival (OS) was 6.10 months, and the median progression-free survival (PFS) was 6.10 months. A significant association was found between trastuzumab treatment cycles and efficacy $(P=0.027)$, cycles and PFS ( $P=0.001)$, and cycles and $\mathrm{OS}(P=0.005)$. Among the five patients who accepted more than five cycles of trastuzumab, the median OS and median PFS achieved 23.83 months and 14.67 months, respectively. Moreover, we have found the correlation between tumor marker changes and efficacy $(P=0.002)$ and HER2 status and PFS $(P=0.027)$. No association was found between HER2 status and OS $(P=0.597)$.

Conclusion: The most common adverse events were left ventricular ejection fraction (LVEF) reduction, fatigue, and anorexia. LVEF reduction was found in seven of 11 patients, but the absolute decline in the LVEF was within 10\% from the baseline. The results of this study suggest that trastuzumab is a feasible option as maintenance or palliative therapy for patients with HER2-positive metastatic GC.

Keywords: HER2-positive, gastric cancer, trastuzumab, efficacy, safety

\section{Introduction}

The incidence of gastric cancer (GC) has been declining in the past few decades worldwide; however, GC is still the fifth most frequently diagnosed cancer and the third leading cause of cancer-related death. ${ }^{1,2}$ It remains the most common type of cancer in East Asian countries, especially in China.

$\mathrm{GC}$ is associated with a poor prognosis. In countries with screening programs, such as South Korea and Japan, GC is more likely to be detected at an early stage, resulting in more favorable 5-year survival rates of 55.6\%-66.0\% $0^{3}$ and $50.0 \%,{ }^{4}$ respectively. Surgery, radiation, and chemotherapy are the main regimens for loco-regional diseases. In other parts of the world, most of the patients are diagnosed at an advanced stage, and poor survival rates are reported. The 5-year survival rate is not more than $30 \%$ for all stages and less than $5 \%$ for stage IV patients. ${ }^{5}$ The median overall survival (OS) of traditional chemotherapy with cytotoxic drugs is only 11 months for patients with advanced GC. ${ }^{6}$ 
In recent years, more and more evidence showed that inflammation plays a pivotal role in carcinogenesis and tumor metastasis. ${ }^{7,8}$ Many laboratory parameters can serve as systemic inflammation indicators and have been investigated as prognostic biomarkers in various kinds of cancers, including neutrophil-to-lymphocyte ratio (NLR) and platelet-to-lymphocyte ratio (PLR). ${ }^{9}$ Also, studies show that elevated NLR and PLR could be investigated as independent prognostic factors in several solid tumors, such as colorectal cancer, ${ }^{10,11}$ non-small-cell lung cancer, ${ }^{12,13}$ and pancreatic cancer, ${ }^{14,15}$ and are associated with poor outcomes. Moreover, several studies have reported the association between NLR, PLR, and prognosis in GC; however, the results are controversial. ${ }^{16,17}$ To date, the role of NLR and PLR in human epidermal growth factor receptor 2 (HER2)-positive metastatic GC is not well studied and remains unclear.

HER2 is a proto-oncogene encoded by ERBB2 on chromosome 17. It is a member of the epidermal growth factor receptor (EGFR) family, and other members include HER1 (ERBB1), HER3 (ERBB3), and HER4 (ERBB4). HER2 can form heterodimers with any of the other three receptors, transmit extracellular signals into cells, activate cell signaling pathways through mitogen-activated protein kinase, phosphoinositide 3-kinase, phospholipase $\mathrm{C}$, protein kinase $\mathrm{C}$, and so on, and ultimately activate transcription. ${ }^{18}$

Expression of HER2 has been found in many tissues, including breast, kidney, gastrointestinal tract, and heart. ${ }^{19}$ Recent studies indicate that HER2 is a key driver of tumor genesis, associated with tumor cell proliferation, adhesion, differentiation, migration, and apoptosis. ${ }^{20,21}$ In addition, HER2 is involved in the development of several types of cancers and associated with poor outcomes, including advanced gastric and gastroesophageal junction (GEJ) cancers. ${ }^{22}$ HER2 overexpression or amplification is observed in approximately $9.8 \%-27 \%$ of the patients with $\mathrm{GC},{ }^{23,24} \mathrm{a}$ higher prevalence in intestinal type and GEJ tumors than in diffuse-type and gastric tumors. ${ }^{25}$

Trastuzumab (Herceptin; Hoffman-La Roche Ltd., Basel, Switzerland), the first monoclonal antibody targeting HER2, combined with chemotherapy, has been considered as first-line treatment recommendation for patients with HER2-positive GC based on the results of the ToGA trial. ToGA trial is a randomized, prospective, multicenter, phase III trial that investigates a significant improvement of the OS addition with trastuzumab compared with chemotherapy alone (13.8 months vs 11 months, $P=0.046){ }^{6}$ This improvement was particularly significant in patients with an HER2 score of immunohistochemistry (IHC) $3+$ or IHC2+ and fluorescence in situ hybridization (FISH) positive. Also, it is noteworthy that trastuzumab did not increase the incidence of adverse events (AEs), which shows good tolerance and a safe profile. ${ }^{6}$

To our knowledge, few studies focus on the trastuzumab as maintenance or palliative therapy for unresectable or metastatic HER2-positive GC patients. In this study, we retrospectively analyzed the information of 11 advanced GC patients with HER2 overexpression or amplification, evaluated the efficacy and safety of trastuzumab as maintenance or palliative therapy, and also attempted to investigate the prognostic factors for trastuzumab treatment and the outcomes of these patients.

\section{Patients and methods}

This study was conducted to evaluate the efficacy and safety of trastuzumab in unresectable or metastatic patients with HER2-positive GC as maintenance or palliative therapy. From April 1, 2013, to November 30, 2017, 11 patients from the Affiliated Cancer Hospital of Zhengzhou University were enrolled in this study. The cutoff follow-up date was December 15, 2017. The inclusion criteria were as follows: 1) Patients diagnosed with stage IV GC certified by histologic pathology or IHC. 2) Not less than 18 years of age. 3) HER2 overexpression or amplification, defined as $\mathrm{IHC} 3+$ or IHC2+ and FISH positive according to the HER2 scoring criteria for GC by Hofmann et al, ${ }^{26}$ confirmed by our experienced pathologists at Department of Pathology. 4) Adequate cardiac function: left ventricular ejection fraction (LVEF) $\geq 55 \%$ before treatment. 5) Patients who received at least one cycle of trastuzumab alone or combined with cytokine-induced killer (CIK) cells but without chemotherapy. 6) Patients with complete clinical data and follow-up information. 7) Staging was conducted according to the Japanese classification, along with the American Joint Committee on Cancer (AJCC) and the Union for International Cancer Control (UICC). The exclusion criteria were as follows: the presence of other active malignancies, severe cardiac problems (eg, chronic heart failure, uncontrolled coronary artery disease), uncontrolled hypertension (systolic blood pressure $>180 \mathrm{mmHg}$ or diastolic $>100 \mathrm{mmHg}$ ), high risk of arrhythmias, and significant valvular disease.

The study was approved by the ethics committee of The Affiliated Cancer Hospital of Zhengzhou University. All patients volunteered to this study and provided written informed consent to receive the therapy.

\section{Efficacy and safety assessment}

The follow-up time was defined as the time from diagnosis to death or the cutoff date. The therapeutic effect was 
evaluated every two cycles of trastuzumab or whenever the patients developed obvious symptoms that indicated disease progression. The evaluation was conducted according to the Response Evaluation Criteria in Solid Tumors (RECIST1.1): complete response (CR), partial response $(\mathrm{PR})$, stable disease (SD), and progressive disease (PD). The overall response rate (ORR) was calculated as follows: $(\mathrm{CR}+\mathrm{PR}) /$ total number of cases $\times 100 \%$. The disease control rate $(\mathrm{DCR})$ was calculated as follows: $(\mathrm{CR}+\mathrm{PR}+\mathrm{SD}) /$ total number of cases $\times 100 \%$. The OS time was defined as the time from the initiation of trastuzumab therapy as maintenance or palliative therapy until death or the last follow-up. The progression-free survival (PFS) time was defined as the time from the initiation of trastuzumab treatment until disease progression or death. AEs were evaluated according to the National Cancer Institute's Common Terminology Criteria for Adverse Events, Version 4.0 (CTC4.0).

\section{Statistical analyses}

The association between efficacy, PFS, OS, and variables was evaluated by non-parametric tests. Pearson or Spearman test was used to assess the association depending on the type of variables. Kaplan-Meier method was conducted to analyze the primary end points. Data analysis was performed using SPSS, Version 24.0 (IBM Corporation, Armonk, NY, USA). All statistical analyses were two-sided, and $P$-value $<0.05$ was considered statistically significant.

\section{Results}

\section{Clinical characteristics of the patients}

A total of 11 patients, including eight males and three females, were recruited for investigation in this study. Median age was 66 years (range 36-77 years). Patients' clinical and pathologic characteristics are shown in Table 1. All patients were diagnosed with HER2+ stage IV GC. Seven (63.64\%) patients had IHC3 + HER2 overexpression, and four (36.36\%) patients had IHC2+ HER2 amplification and FISH positive. The Eastern Cooperative Oncology Group (ECOG) performance status (PS) scores were 1-3. Seven patients had more than three metastatic sites, and anemia was found in five patients once diagnosed. The most common sites of relapse were lymph node $(8,72.73 \%)$, liver $(6,54.55 \%)$, and lungs $(5,45.45 \%)$. Four $(36.36 \%)$ patients accepted trastuzumab alone as palliative therapy, five $(45.45 \%)$ patients applied trastuzumab alone and two (18.18\%) patients used trastuzumab combined with CIK cells as maintenance therapy followed by the chemotherapy plus trastuzumab. Before the treatment of trastuzumab, 10 patients had received surgery, chemotherapy, radiotherapy, Apatinib, and autologous CIK cell therapy. One patient was treated with trastuzumab alone as palliative therapy once diagnosed because of poor PS and severe chronic obstructive pulmonary disease (Case 4). The median treatment cycles of trastuzumab were 4 (range 1-24). Trastuzumab was administered at a dose of $8 \mathrm{mg} / \mathrm{kg}$ or $6 \mathrm{mg} / \mathrm{kg}$ on day 1 of the first cycle and then a loading dose of $6 \mathrm{mg} / \mathrm{kg}$ or $4 \mathrm{mg} / \mathrm{kg}$ every 3 weeks, or at a dose of $4 \mathrm{mg} / \mathrm{kg}$ every 2 weeks until disease progression, unacceptable toxicity, or withdrawal of consent.

\section{Efficacy evaluation}

Among the 11 patients, one $(9.10 \%)$ achieved PR and the median PFS exceeded 22.73 months (Figures 1 and 2). Six patients $(54.55 \%)$ achieved SD and four patients $(36.36 \%)$ were evaluated as PD (Table 1). The ORR was $9.10 \%$ (1/11), and the DCR was $63.64 \%(7 / 11)$. The median OS was 6.10 months, and median PFS was 6.10 months (Figure 3). Noteworthy, among the five patients who accepted more than five cycles of trastuzumab, the median OS and median PFS achieved 23.83 months and 14.67 months, respectively (Table 1).

\section{Correlation study}

The results of correlation study indicated that there was a definite association between trastuzumab treatment cycles and efficacy $(P=0.027)$, cycles and PFS $(P=0.001)$, and cycles and OS $(P=0.005)$. Tumor marker changes had association with efficacy $(P=0.002)$. In addition, the correlation was found between HER2 status and PFS $(P=0.027)$ but not between HER2 status and OS $(P=0.597)$. No correlation was found between NLR, PLR, and prognosis. No association was found between other agents and efficacy, PFS, and OS by bivariate analyses (Table 2 ).

\section{AEs' observation}

The AEs associated with trastuzumab are listed in Table 3. Briefly, most of the AEs were asymptomatic or mild (grade 1) or could easily be controlled by symptomatic interventions (grade 2). Only two grade 3 AEs occurred in LVEF reduction and fatigue. No grade 4 AEs occurred. The most common side effects were LVEF reduction (7/11, 63.64\%), fatigue $(4 / 11,36.36 \%)$, and anorexia $(4 / 11,36.36 \%)$.

During a median follow-up period of 20.13 months (range 6.00-35.97 months), we found abnormal drop of LVEF in seven of 11 patients (63.64\%), increase in LVEF in two of 11 patients $(18.18 \%)$, and no available data in two of 11 patients $(18.18 \%)$ because of terminal stage of tumor (Figure 4). Trastuzumab-induced cardiotoxicity (TIC), which was defined as an absolute decline in LVEF of at least $10 \%$ 
Table I Demographics and outcomes of the II patients

\begin{tabular}{|c|c|c|c|c|c|c|c|c|c|c|}
\hline Patient & Age & Gender & $\begin{array}{l}\text { ECOG } \\
\text { status }\end{array}$ & BMI & Pathology & $\begin{array}{l}\text { HER2 } \\
\text { status }\end{array}$ & Metastatic sites & Smoke & $\begin{array}{l}\text { Alcohol } \\
\text { intake }\end{array}$ & $\begin{array}{l}\text { HB level before } \\
\text { treatment ( }(\mathrm{L} / \mathrm{L})\end{array}$ \\
\hline I & 68 & Male & I & 25.86 & Adenocarcinoma & $\mathrm{IHC} 3+$ & $\begin{array}{l}\text { Liver, lung, and } \\
\text { lymph node }\end{array}$ & Yes & Yes & 128 \\
\hline 2 & 75 & Female & I & 16.80 & $\begin{array}{l}\text { Papillary tubular } \\
\text { adenocarcinoma }\end{array}$ & $\begin{array}{l}\mathrm{IHC} 2+\text { and } \\
\text { FISH positive }\end{array}$ & $\begin{array}{l}\text { Lung, omentum, } \\
\text { lymph node, and } \\
\text { peritoneum }\end{array}$ & No & No & 130 \\
\hline 3 & 47 & Female & I & 25.7 & $\begin{array}{l}\text { Ulcerative } \\
\text { adenocarcinoma }\end{array}$ & $\mathrm{IHC} 3+$ & $\begin{array}{l}\text { Omentum, } \\
\text { lymph node, and } \\
\text { peritoneum }\end{array}$ & No & No & 126 \\
\hline 4 & 77 & Male & 3 & 24.5 & Adenocarcinoma & $\mathrm{IHC} 3+$ & Liver & No & No & 100 \\
\hline 5 & 64 & Male & 3 & 22.5 & Adenocarcinoma & $\begin{array}{l}\mathrm{IHC} 2+\text { and } \\
\text { FISH positive }\end{array}$ & Liver, lung, and bone & Yes & Yes & 151 \\
\hline 6 & 50 & Male & I & 24.1 & Adenocarcinoma & FISH positive & Liver and lymph node & No & Yes & 126 \\
\hline 7 & 76 & Male & I & 17.3 & Adenocarcinoma & FISH positive & Liver and lung & Yes & Yes & 77 \\
\hline 8 & 76 & Male & 1 & 20.3 & Adenocarcinoma & $\mathrm{IHC} 3+$ & $\begin{array}{l}\text { Bone, lymph node, } \\
\text { and adrenal gland }\end{array}$ & No & No & 103 \\
\hline 9 & 50 & Male & I & 25.1 & $\begin{array}{l}\text { Mucinous } \\
\text { adenocarcinoma }\end{array}$ & $\mathrm{IHC} 3+$ & Lymph node and liver & Yes & Yes & 109 \\
\hline 10 & 66 & Female & I & 24.6 & Adenocarcinoma & $\mathrm{IHC} 3+$ & $\begin{array}{l}\text { Lymph node, lung, } \\
\text { omentum, and } \\
\text { adrenal gland }\end{array}$ & No & No & 101 \\
\hline II & 36 & Male & I & 18.3 & Adenocarcinoma & $\mathrm{IHC} 3+$ & $\begin{array}{l}\text { Bone, abdominal } \\
\text { cavity, and lymph } \\
\text { node }\end{array}$ & No & No & 140 \\
\hline
\end{tabular}

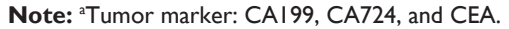

Abbreviations: BMI, body mass index; CIK, cytokine-induced killer; ECOG, Eastern Cooperative Oncology Group; FISH, fluorescence in situ hybridization; HB, hemoglobin; HER2, human epidermal growth factor receptor 2; IHC, immunohistochemistry; NLR, neutrophil-to-lymphocyte ratio; OS, overall survival; PFS, progression-free survival; PD, progressive disease; PDI, programmed cell death protein- I; PLR, platelet-to-lymphocyte ratio; Q2W, every 2 weeks; SD, stable disease.

from the baseline to a value less than $55 \%$, was not observed in this study. The median baseline LVEF of the 11 patients was $69 \%$ (range $60 \%-71 \%$ ). LVEF was measured every three or four cycles of trastuzumab treatment, and the median number of LVEF assessments was 4 (range 1-7). Among the seven patients, one patient terminated trastuzumab treatment because of heart discomfort, and LVEF reduction in the other patients was reversible, could recover spontaneously at the interval of treatment, and did not affect the continuation of therapy.

\section{Discussion}

GC is a common malignant tumor of the digestive tract worldwide, especially in China. Most of the patients are



HER2 IHC staining original magnification (200x)

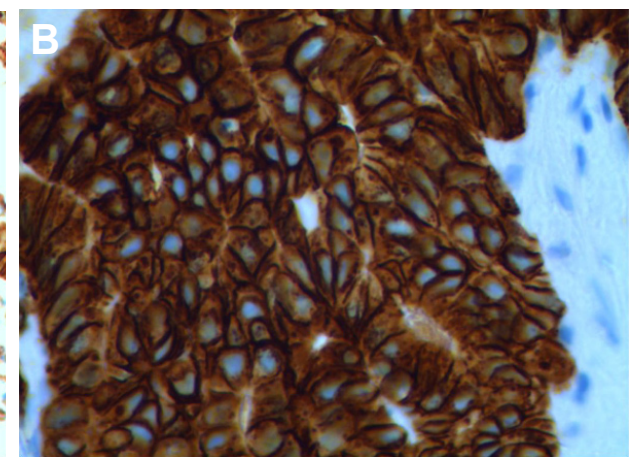

HER2 IHC staining original magnification (400x)

Figure I HER2 status of the PR patient.

Abbreviations: HER2, human epidermal growth factor receptor 2; IHC, immunohistochemistry; PR, partial response. 


\begin{tabular}{|c|c|c|c|c|c|c|c|c|c|}
\hline $\begin{array}{l}\text { NLR } \\
\text { before } \\
\text { treatment }\end{array}$ & $\begin{array}{l}\text { PLR } \\
\text { before } \\
\text { treatment }\end{array}$ & $\begin{array}{l}\text { Tumor } \\
\text { marker } \\
\text { changes }^{\mathrm{a}}\end{array}$ & $\begin{array}{l}\text { Weight } \\
\text { loss after } \\
\text { treatment }\end{array}$ & $\begin{array}{l}\text { Treatment before } \\
\text { trastuzumab }\end{array}$ & $\begin{array}{l}\text { Dose } \\
(\mathrm{mg} / \mathrm{kg})\end{array}$ & Cycles & Efficacy & $\begin{array}{l}\text { PFS } \\
\text { (months) }\end{array}$ & $\begin{array}{l}\text { OS } \\
\text { (months) }\end{array}$ \\
\hline \multirow[t]{2}{*}{2.29} & 156.65 & Increase & No & Chemotherapy and CIK & 8 & 21 & SD & 14.93 & 28.83 \\
\hline & & & & & 6 & & & & \\
\hline \multirow[t]{2}{*}{0.71} & 48.48 & Increase & Yes & Chemotherapy+trastuzumab & 6 & 11 & SD & 3.80 & 17.03 \\
\hline & & & & Chemotherapy & 4 & & & & \\
\hline 1.82 & 109.95 & Decrease & No & Chemotherapy+trastuzumab & 6 & 4 & SD & 4.93 & $4.93+$ \\
\hline \multirow[t]{2}{*}{2.86} & 154.54 & Decrease & Yes & No & 8 & 24 & PR & 22.73 & 29.53 \\
\hline & & & & & 6 & & & & \\
\hline 4.15 & 146.20 & Increase & Yes & $\begin{array}{l}\text { Chemotherapy and } \\
\text { apatinib+anti-PDI antibody }\end{array}$ & 8 & 1 & PD & 0.47 & 0.47 \\
\hline 2.20 & 159.33 & Increase & Yes & Chemotherapy+trastuzumab & 8 & 5 & PD & 5.53 & 30.10 \\
\hline \multirow[t]{2}{*}{3.70} & 307.79 & Decrease & Yes & Surgery, chemotherapy, and & 4 & 3 & SD & 3.37 & $3.37+$ \\
\hline & & & & Apatinib & Q2W & & & & \\
\hline 3.60 & 125.00 & Decrease & Yes & Surgery and chemotherapy & 6 & 7 & SD & 14.67 & 21.07 \\
\hline 2.89 & $|80.4|$ & Decrease & No & $\begin{array}{l}\text { Surgery and chemotherapy, } \\
\text { and radiotherapy }\end{array}$ & 6 & 4 & SD & 6.10 & $6.10+$ \\
\hline 2.31 & 156.85 & Increase & No & $\begin{array}{l}\text { Pertuzumab+trastuzumab+ } \\
\text { chemotherapy, } \\
\text { trastuzumab+chemotharapy }\end{array}$ & 6 & 2 & PD & 3.83 & 3.83 \\
\hline 16.92 & 124.24 & Increase & Loss & $\begin{array}{l}\text { Chemotherapy, apatinib, } \\
\text { chemotherapy+trastuzumab }\end{array}$ & 6 & 1 & PD & 3.83 & 3.83 \\
\hline
\end{tabular}

diagnosed at advanced stage. HER2-positive GC is a unique subtype of this disease, and different strategies and regimens need to be explored for the treatment. The HER2 oncogene is located on chromosome 17q12 and can form active heterodimers with any of the other three receptors. ${ }^{18}$ Phosphorylation of tyrosine residues within the cytoplasmic domain through HER2 and its receptor dimerization can result in activating of various signaling

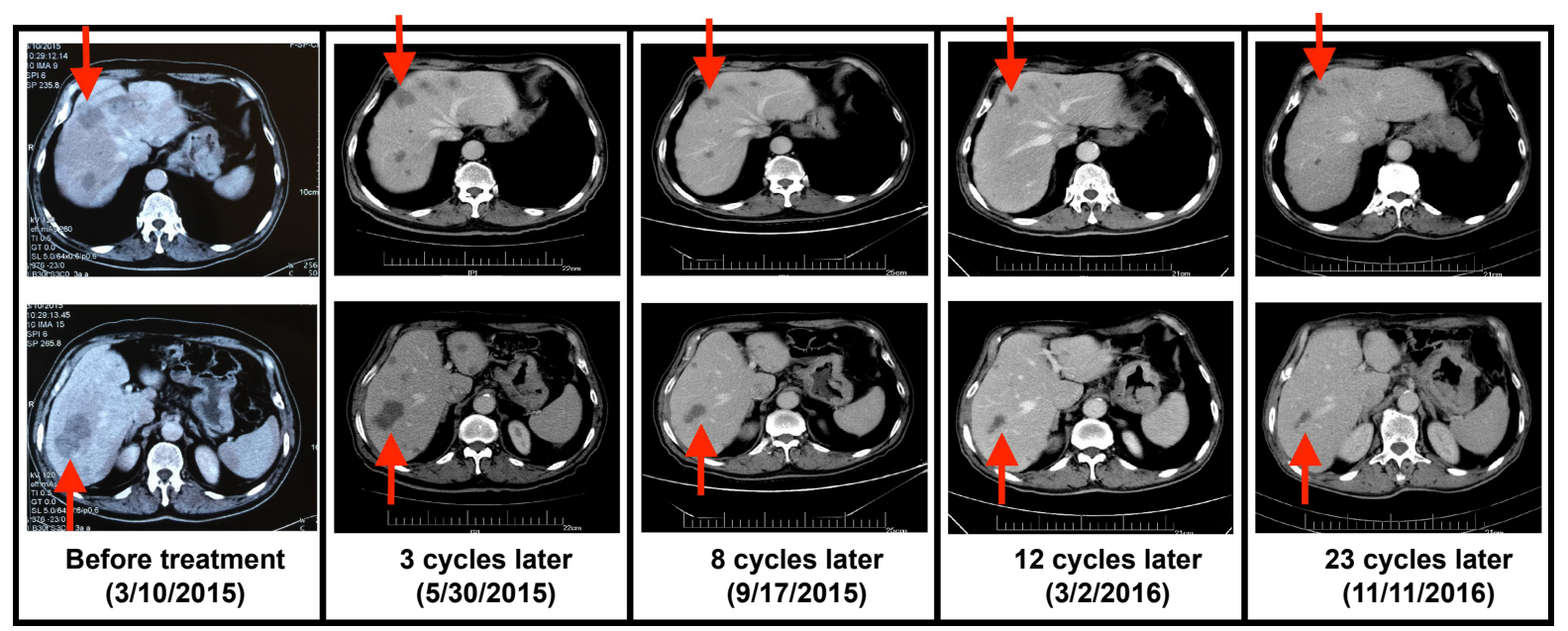

Figure 2 The CT images of the PR patient during trastuzumab treatment.

Note: We choose two major lesions in liver $\mathrm{S} 6$ and $\mathrm{S} 7 / 8$ segment as target shown by red arrow.

Abbreviations: CT, computed tomography; PR, partial response. 

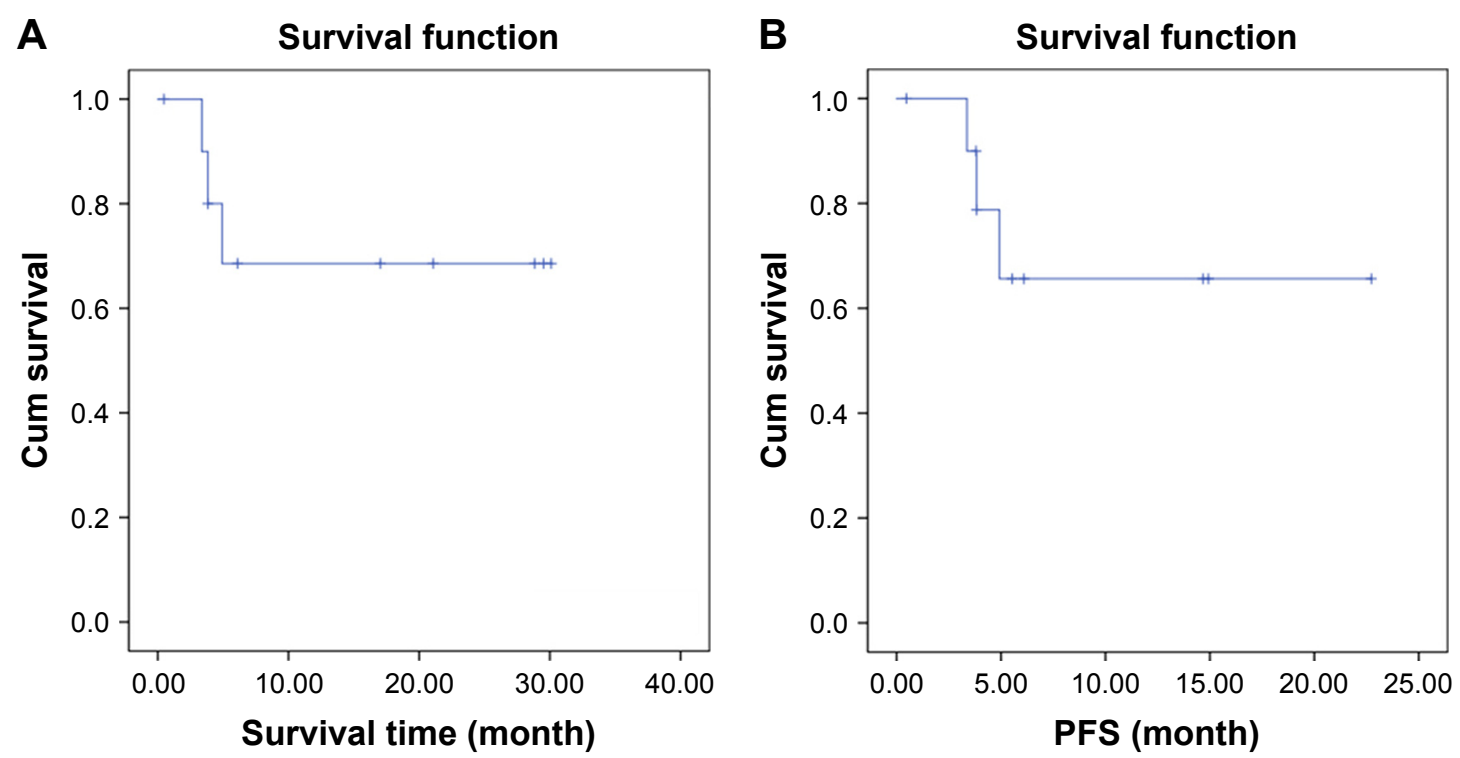

$\neg$ Survival function + Censored

Figure 3 The Kaplan-Meier curves of OS (A) and PFS (B) for all II patients.

Abbreviations: Cum, Cumulative; OS, overall survival; PFS, progression-free survival.

pathways involved in cellular proliferation, transcription, motility, and apoptosis. ${ }^{27}$

Evidence showed that HER2-positive breast cancer accounted for $20 \%-25 \%$ of cases and indicated poor outcomes. ${ }^{28}$ In GC, many studies have evaluated the relationship between HER2 status and prognosis; however, the results remain controversial. Some studies suggested that frequently HER2 positivity in advanced GC could be involved in tumor progression and poor outcomes. ${ }^{22,29}$ Further analyses found that poorer prognosis in HER2-positive patients was significantly correlated with age and histopathologic type, ${ }^{30}$ whereas some studies failed to establish the prognostic value of HER2 positivity and prognosis ${ }^{31}$ or exhibited contradictory evidence that median OS was longer in HER2-positive patients than in HER2-negative patients. ${ }^{23,25}$ Generally speaking, HER2 overexpression or amplification is predictive of response to HER2-targeted therapy. ${ }^{32}$

Trastuzumab, a humanized IgG1 antibody targeting the extracellular domain of HER2 receptor through binding to its Fab segment, thus inhibits PI3K/Akt activation and downstream signaling pathways, ${ }^{33}$ attributes to angiogenesis, ${ }^{34}$ and possesses antibody-dependent cell-mediated cytotoxicity

Table 2 Association between efficacy, PFS, OS and variables

\begin{tabular}{|c|c|c|c|c|c|c|}
\hline \multirow[t]{2}{*}{ Variables } & \multicolumn{2}{|c|}{ Efficacy } & \multicolumn{2}{|l|}{ PFS } & \multicolumn{2}{|l|}{ OS } \\
\hline & $R$ & $P$-value & $R$ & $P$-value & $R$ & $P$-value \\
\hline Age & 0.510 & 0.109 & 0.428 & 0.189 & 0.322 & 0.335 \\
\hline Gender & -0.039 & 0.910 & 0.291 & 0.385 & 0.162 & 0.635 \\
\hline ECOG & 0.134 & 0.695 & -0.299 & 0.372 & 0.072 & 0.834 \\
\hline BMI & 0.120 & 0.726 & 0.320 & 0.337 & $0.24 I$ & 0.476 \\
\hline Smoke & 0.179 & 0.599 & -0.180 & 0.597 & -0.359 & 0.278 \\
\hline Alcohol & -0.069 & 0.840 & -0.116 & 0.735 & -0.058 & 0.866 \\
\hline HER2 status & 0.214 & 0.527 & 0.659 & 0.027 & 0.180 & 0.597 \\
\hline Metastatic sites & -0.222 & 0.511 & -0.404 & 0.218 & -0.344 & 0.301 \\
\hline Preliminary HB level & -0.389 & 0.237 & -0.316 & 0.344 & -0.054 & 0.874 \\
\hline NLR before treatment & -0.299 & 0.372 & -0.171 & 0.615 & -0.322 & 0.334 \\
\hline PLR before treatment & -0.060 & 0.861 & -0.048 & 0.889 & -0.196 & 0.563 \\
\hline Tumor marker changes & -0.828 & 0.002 & -0.174 & 0.610 & -0.116 & 0.735 \\
\hline Weight loss & -0.463 & 0.152 & -0.388 & 0.238 & -0.129 & 0.705 \\
\hline Cycles & 0.660 & 0.027 & 0.859 & 0.001 & 0.780 & 0.005 \\
\hline
\end{tabular}

Abbreviations: BMI, body mass index; ECOG, Eastern Cooperative Oncology Group; HB, hemoglobin; HER2, human epidermal growth factor receptor 2; NLR, neutrophilto-lymphocyte ratio; OS, overall survival; PFS, progression-free survival; PLR, platelet-to-lymphocyte ratio. 
Table 3 Association between efficacy, PFS, OS, and variables

\begin{tabular}{|c|c|c|c|c|}
\hline Toxicities & $\begin{array}{l}\text { Grade I, } \\
\text { n (\%) }\end{array}$ & $\begin{array}{l}\text { Grade 2, } \\
\text { n (\%) }\end{array}$ & $\begin{array}{l}\text { Grade 3, } \\
\text { n (\%) }\end{array}$ & $\begin{array}{l}\text { Total, } \\
\text { n (\%) }\end{array}$ \\
\hline LVEF reduction & $4(36.36)$ & $2(18.18)$ & I (9.09) & $7(63.64)$ \\
\hline Fatigue & $2(18.18)$ & I (9.09) & I (9.09) & $4(36.36)$ \\
\hline Anorexia & $2(18.18)$ & $2(18.18)$ & - & $4(36.36)$ \\
\hline Nausea & I (9.09) & I (9.09) & - & $2(18.18)$ \\
\hline Bloating & I (9.09) & I (9.09) & - & $2(18.18)$ \\
\hline Insomnia & I (9.09) & I (9.09) & - & $2(18.18)$ \\
\hline Anemia & I (9.09) & I (9.09) & - & $2(18.18)$ \\
\hline Chest pain-cardiac & I (9.09) & & - & I (9.09) \\
\hline Chest tightness & I (9.09) & - & - & I (9.09) \\
\hline Palpitation & I (9.09) & - & - & I (9.09) \\
\hline Platelet count decreased & I (9.09) & - & - & I (9.09) \\
\hline Abdominal pain & I (9.09) & - & - & I (9.09) \\
\hline Constipation & I (9.09) & - & - & I (9.09) \\
\hline
\end{tabular}

Abbreviations: LVEF, left ventricular ejection fraction; OS, overall survival; PFS, progression-free survival.

(ADCC) through its Fe segment and natural killer (NK) cells. ${ }^{35}$ Trastuzumab monotherapy is used as maintenance therapy for patients with breast cancer based on the HERA trial, which concluded that 1 year of trastuzumab maintenance therapy should be considered as the standard treatment and could significantly improve OS and disease-free survival (DFS) for patients with HER2-positive advanced breast cancer. ${ }^{36}$

But in HER2-positive advanced GC, only sporadic cases and small case series appeared. A retrospective analysis, which included seven patients with HER2-positive advanced GC who received trastuzumab as maintenance therapy, showed that the median PFS was 14.6 months and the median OS was 16.4 months. ${ }^{37}$ The German HerMES observational study evaluated the efficacy, safety, and feasibility of trastuzumab in untreated patients with HER2-positive metastatic GC as maintenance therapy, and the median PFS was 6.9 months. $^{38}$

In the ToGA trial, trastuzumab combined with chemotherapy could significantly improve OS in patients with HER2-positive advanced gastric or gastroesophageal cancer compared with chemotherapy alone. In addition, continuing trastuzumab therapy until disease progression might extend OS, which supported the fact that maintenance therapy with trastuzumab was a feasible regimen. ${ }^{6}$

In terms of efficacy prediction, the ToGA trial also indicated that HER 2 status could be used to select potential people benefiting from the treatment of trastuzumab. Study has shown that in real world, HER2-positive GC patients can indeed benefit from trastuzumab therapy and that HER2 gene amplification level can be used to predict the sensitivity of trastuzumab. ${ }^{39}$

CIK cells are a heterogeneous type of effector CD8 $\mathrm{T}$ cells with $\mathrm{T}$ cell receptor (TCR) specificities, possessing non-major histocompatibility complex (MHC)-restricted cytolytic and potent broader spectrum antitumor activities. ${ }^{40}$ In various solid tumors including GC, CIK cells have provided encouraging results in improving ORR, OS, and quality of life when combined with standard therapeutic procedures. ${ }^{41}$ The benefits of the treatment with trastuzumab

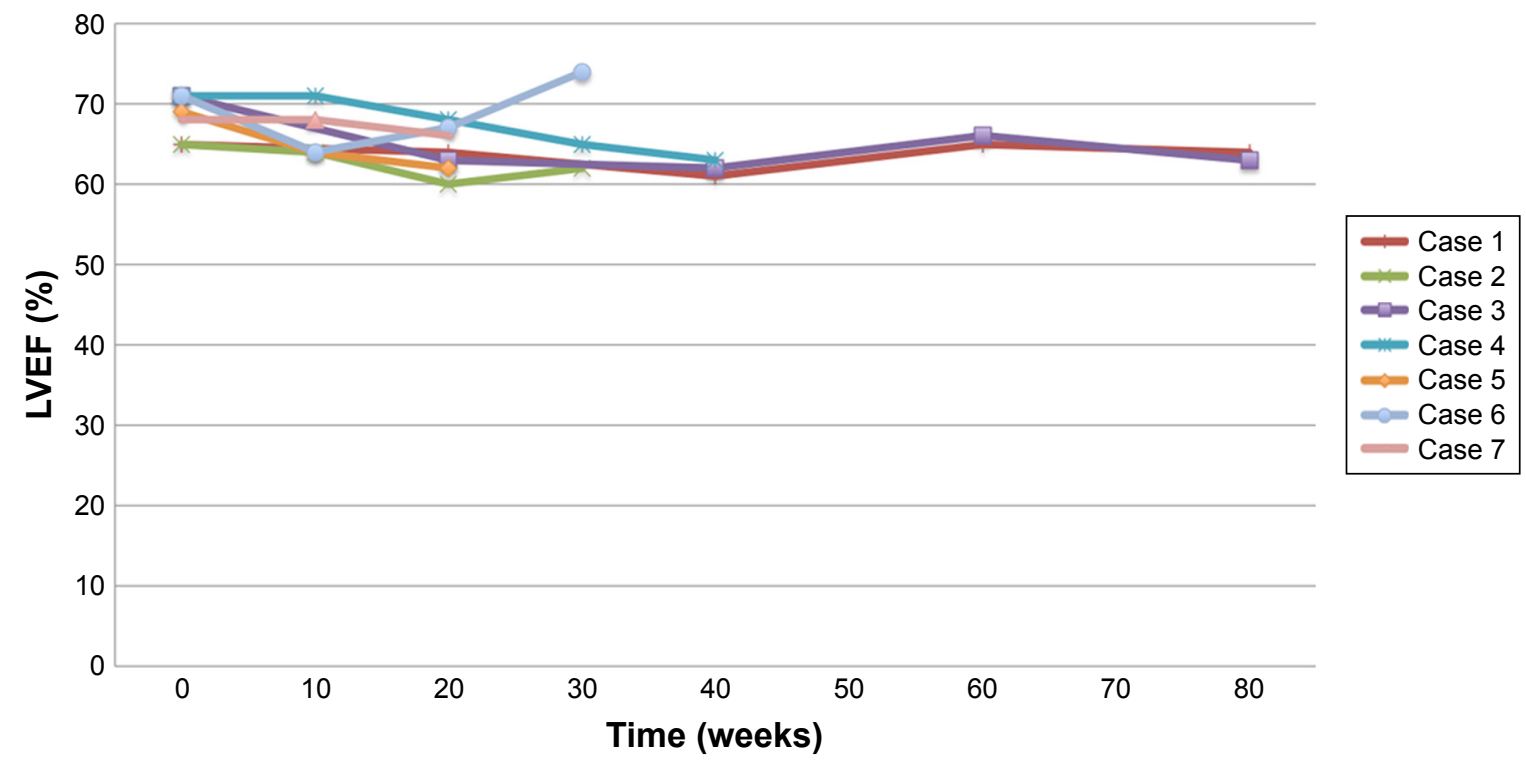

Figure 4 LVEF levels of the seven patients during trastuzumab treatment. Abbreviation: LVEF, left ventricular ejection fraction. 
combined with CIK cells in advanced HER2-positive GC remain unclear.

Recently, study has shown that high NLR and PLR were significantly associated with poor prognosis in earlystage and local advanced GC. ${ }^{17}$ Meta-analysis showed that elevated PLR could be a prognostic indicator for poor OS in GC patients, especially in Caucasians and at advanced stage, but not for poor DFS. ${ }^{42}$ An elevated neutrophil count promotes tumor growth and metastasis by remodeling the extracellular matrix, releasing reactive oxygen species, and suppressing lymphocyte activity. ${ }^{43}$ In addition, the presence of tumor cells affects platelets and causes cancer-induced thrombosis. As a result of this activation, platelets release a number of growth factors that support tumor growth, angiogenesis, and metastasis. ${ }^{44}$

Previous evidence suggested that platelets played multiple roles in inflammatory process including facilitated neutrophil adhesion to endothelium through releasing chemokines and cytokines and promoted tumor progression through facilitation of neoangiogenesis and production of adhesion molecules. ${ }^{45}$ In contrast, lymphocytes are known as inhibiting tumor cell proliferation and metastasis, ${ }^{46}$ mediating ADCC effects. ${ }^{47}$ Therefore, there is a biological rationale for using NLR and PLR to predict clinical outcomes in GC.

In this study, four patients accepted trastuzumab alone as palliative therapy, five patients applied trastuzumab alone, and two patients used trastuzumab combined with CIK cells as maintenance therapy. Among the 11 patients, one achieved PR, six achieved SD, and four were evaluated as PD. The ORR was $9.10 \%$, and the DCR was $63.64 \%$. The median OS was 6.10 months, and the median PFS was 6.10 months. A significant association was found between trastuzumab treatment cycles and efficacy $(P=0.027)$, cycles and PFS $(P=0.001)$, and cycles and $\mathrm{OS}(P=0.005)$. Among the 5 patients who accepted more than five cycles of trastuzumab, the median OS and median PFS achieved 23.83 months and 14.67 months, respectively. Moreover, we have found the association between tumor marker changes and efficacy $(P=0.002)$, HER2 status, and PFS $(P=0.027)$. But no correlation was found between HER2 status and OS $(P=0.597)$, among NLR, PLR, and outcomes due to case number limit. The results of this study showed that trastuzumab alone or combined with CIK cell therapy is a feasible option as maintenance of palliative therapy for patients with HER2-positive GC, especially for older and poor PS cases. With the increase in treatment cycle, efficacy will be better, and the PFS and OS may be longer. HER2 status may have impact on PFS.

In addition, side effects of trastuzumab treatment were mild and manageable. The most common AEs were LVEF reduction, fatigue, and anorexia. Only two grade 3 AEs occurred in LVEF reduction and fatigue, respectively. LVEF reduction was found in seven of 11 patients, but the absolute decline in the LVEF was within 10\% from the baseline.

Cardiotoxicity is one of the well-known toxicities caused by trastuzumab. In cardiac tissues, HER2 works as a co-receptor, which promotes cardiomyocyte proliferation, contractile function, and survival. ${ }^{48}$ Block of HER2 will finally lead to cardiomyocyte death through a change in the anti-apoptotic/proapoptotic protein ratio. ${ }^{49}$ Another possible mechanism for trastuzumab-associated cardiotoxicity is represented by mitochondrial dysfunction and disruption of cellular energetic. ${ }^{50}$ Cardiotoxicity induced by trastuzumab was thought to be generally reversible, not dose-dependent, or functionally related to the contractile elements of the heart. ${ }^{51}$ For HER2-positive GC patients, the rate of all cardiac AEs, grade 3 or 4 cardiac AEs, and a significant drop in LVEF to an absolute value of $<50 \%$ were $6 \%, 1 \%$, and $5 \%$, respectively, in the ToGA trial. ${ }^{6}$

Cardiac risk scores have been developed to predict the risk of cardiotoxicity associated with trastuzumab in HER2positive breast cancer patients, including age, obesity, hypertension, diabetes mellitus, renal dysfunction, pre-existing cardiovascular disease, anthracycline-based chemotherapy, and chest radiation therapy. ${ }^{52-54}$ These results have not been confirmed in either this study or other previous studies in GC. Our results verified that the LVEF reduction in trastuzumab was reversible, could recover spontaneously, and does not affect the following therapy.

\section{Conclusion}

This study retrospectively evaluated the efficacy and safety of trastuzumab as maintenance or palliative therapy in HER2positive metastatic GC patients. The study of gene molecular type shows that GC is actually a highly heterogeneous disease and different from what we thought before. Trastuzumab combined with other target drugs is a new way to enhance the efficacy or reverse the resistance of HER 2 treatment. ${ }^{55,56}$ With the approval of anti-programmed cell death protein-1 (PD1) inhibitors in advanced GC, a new era of immunotherapy is arriving. ${ }^{57}$ Promising results are expected by combining PD1 blockade with anti-HER2 agents. In the future, the treatment options for advanced HER2-positive GC will be more diverse, precise, and individual.

\section{Acknowledgments}

The authors are grateful to all staff who contributed to this study. This work was supported by Henan Medical Science and Technique Foundation (No 201701030). 


\section{Disclosure}

The authors report no conflicts of interest in this work.

\section{References}

1. Torre LA, Bray F, Siegel RL, et al. Global cancer statistics, 2012. CA Cancer J Clin. 2015;65(2):87-108.

2. GLOBOCAN. Stomach Cancer: Estimated Incidence, Mortality and Prevalence Worldwide in 2012; 2012.

3. Park JM, Kim YH. Current approaches to gastric cancer in Korea. Gastrointest Cancer Res. 2008;2(3):137-144.

4. Inoue M, Tsugane S. Epidemiology of gastric cancer in Japan. Postgrad Med J. 2005;81(957):419-424.

5. Siegel RL, Miller KD, Jemal A. Cancer statistics, 2015. Ca Cancer J Clin. 2015;65(1):5-29.

6. Bang YJ, van Cutsem E, Feyereislova A, et al. Trastuzumab in combination with chemotherapy versus chemotherapy alone for treatment of HER2-positive advanced gastric or gastro-oesophageal junction cancer (ToGA): a phase 3, open-label, randomised controlled trial. Lancet. 2010;376(9742):687-697.

7. Karin M. Nuclear factor-kappaB in cancer development and progression. Nature. 2006;441(7092):431-436.

8. Hanahan D, Weinberg RA. Hallmarks of cancer: the next generation. Cell. 2011;144(5):646-674.

9. Proctor MJ, Morrison DS, Talwar D, et al. A comparison of inflammationbased prognostic scores in patients with cancer. A Glasgow Inflammation Outcome Study. Eur J Cancer. 2011;47(17):2633-2641.

10. Ishizuka M, Nagata H, Takagi K, Iwasaki Y, Kubota K. Combination of platelet count and neutrophil to lymphocyte ratio is a useful predictor of postoperative survival in patients with colorectal cancer. $\mathrm{Br} J$ Cancer. 2013;109(2):401-407.

11. Kim JH, Lee JY, Kim HK, et al. Prognostic significance of the neutrophil-tolymphocyte ratio and platelet-to-lymphocyte ratio in patients with stage III and IV colorectal cancer. World J Gastroenterol. 2017;23(3):505-515.

12. Liu H, Wu Y, Wang Z, et al. Pretreatment platelet-to-lymphocyte ratio (PLR) as a predictor of response to first-line platinum-based chemotherapy and prognosis for patients with non-small cell lung cancer. J Thorac Dis. 2013;5(6):783-789.

13. Peng B, Wang YH, Liu YM, Ma LX. Prognostic significance of the neutrophil to lymphocyte ratio in patients with non-small cell lung cancer: a systemic review and meta-analysis. Int J Clin Exp Med. 2015; 8(3):3098-3106

14. Bhatti I, Peacock O, Lloyd G, Larvin M, Hall RI. Preoperative hematologic markers as independent predictors of prognosis in resected pancreatic ductal adenocarcinoma: neutrophil-lymphocyte versus platelet-lymphocyte ratio. Am J Surg. 2010;200(2):197-203.

15. Stotz M, Gerger A, Eisner F, et al. Increased neutrophil-lymphocyte ratio is a poor prognostic factor in patients with primary operable and inoperable pancreatic cancer. Br J Cancer. 2013;109(2):416-421.

16. Lee S, Oh SY, Kim SH, et al. Prognostic significance of neutrophil lymphocyte ratio and platelet lymphocyte ratio in advanced gastric cancer patients treated with FOLFOX chemotherapy. BMC Cancer. 2013;13:350

17. Kim EY, Lee JW, Yoo HM, Park CH, Song KY. The Platelet-toLymphocyte Ratio Versus Neutrophil-to-Lymphocyte Ratio: Which is Better as a Prognostic Factor in Gastric Cancer? Ann Surg Oncol. 2015; 22(13):4363-4370.

18. Olayioye MA. Update on HER-2 as a target for cancer therapy: intracellular signaling pathways of ErbB2/HER-2 and family members. Breast Cancer Res. 2001;3(6):385-389.

19. Yamamoto T, Ikawa S, Akiyama T, et al. Similarity of protein encoded by the human c-erb-B-2 gene to epidermal growth factor receptor. Nature. 1986;319(6050):230-234

20. Ménard S, Pupa SM, Campiglio M, Tagliabue E. Biologic and therapeutic role of HER2 in cancer. Oncogene. 2003;22(42):6570-6578.

21. Hechtman JF, Polydorides AD. HER2/neu gene amplification and protein overexpression in gastric and gastroesophageal junction adenocarcinoma: a review of histopathology, diagnostic testing, and clinical implications. Arch Pathol Lab Med. 2012;136(6):691-697.
22. Kim KC, Koh YW, Chang HM, et al. Evaluation of HER2 protein expression in gastric carcinomas: comparative analysis of 1,414 cases of whole-tissue sections and 595 cases of tissue microarrays. Ann Surg Oncol. 2011;18(10):2833-2840.

23. Chua TC, Merrett ND. Clinicopathologic factors associated with HER2-positive gastric cancer and its impact on survival outcomes - a systematic review. Int J Cancer. 2012;130(12):2845-2856.

24. Yoon HH, Shi Q, Sukov WR, et al. Association of HER2/ErbB2 expression and gene amplification with pathologic features and prognosis in esophageal adenocarcinomas. Clin Cancer Res. 2012;18(2):546-554.

25. Janjigian YY, Werner D, Pauligk C, et al. Prognosis of metastatic gastric and gastroesophageal junction cancer by HER2 status: a European and USA International collaborative analysis. Ann Oncol. 2012;23(10): 2656-2662.

26. Hofmann M, Stoss O, Shi D, et al. Assessment of a HER2 scoring system for gastric cancer: results from a validation study. Histopathology. 2008;52(7):797-805.

27. Rubin I, Yarden Y. The basic biology of HER2. Ann Oncol. 2001; 12(Suppl 1):S3-S8.

28. Acharyya S, Oskarsson T, Vanharanta S, et al. A CXCL1 paracrine network links cancer chemoresistance and metastasis. Cell. 2012; 150(1):165-178

29. Cho J, Jeong J, Sung J, et al. A large cohort of consecutive patients confirmed frequent HER2 positivity in gastric carcinomas with advanced stages. Ann Surg Oncol. 2013;20(Suppl 3):477-484.

30. Tanner M, Hollmén M, Junttila TT, et al. Amplification of HER-2 in gastric carcinoma: association with Topoisomerase IIalpha gene amplification, intestinal type, poor prognosis and sensitivity to trastuzumab. Ann Oncol. 2005;16(2):273-278.

31. Terashima M, Ochiai A, Kitada K, et al. Impact of human epidermal growth factor receptor (EGFR) and ERBB2 (HER2) expressions on survival in patients with stage II/III gastric cancer, enrolled in the ACTS-GC study. Journal of Clinical Oncology. 2011;29(15_supp1):4013Abstract 4013.

32. Moelans CB, van Diest PJ, Milne AN, Offerhaus GJ. Her-2/neu testing and therapy in gastroesophageal adenocarcinoma. Patholog Res Int. 2010;2011:674182.

33. Arienti C, Zanoni M, Pignatta S, et al. Preclinical evidence of multiple mechanisms underlying trastuzumab resistance in gastric cancer. Oncotarget. 2016;7(14):18424-18439.

34. Izumi Y, Xu L, di Tomaso E, Fukumura D, Jain RK. Tumour biology: herceptin acts as an anti-angiogenic cocktail. Nature. 2002;416(6878): 279-280.

35. Shi Y, Fan X, Meng W, et al. Engagement of immune effector cells by trastuzumab induces HER2/ERBB2 downregulation in cancer cells through STAT1 activation. Breast Cancer Res. 2014;16(2):R33.

36. Cameron D, Piccart-Gebhart MJ, Gelber RD, et al. 11 years' follow-up of trastuzumab after adjuvant chemotherapy in HER2-positive early breast cancer: final analysis of the HERceptin Adjuvant (HERA) trial. Lancet. 2017;389(10075):1195-1205.

37. Palacio S, Loaiza-Bonilla A, Kittaneh M, et al. Successful use of Trastuzumab with anthracycline-based chemotherapy followed by trastuzumab maintenance in patients with advanced HER2-positive gastric cancer. Anticancer Res. 2014;34(1):301-306.

38. Hegewisch-Becker S, Moorahrend E, Kröning H, et al. Trastuzumab (TRA) in combination with different first-line chemotherapies for treatment of HER2-positive metastatic gastric or gastroesophageal junction cancer (MGC): findings from the German noninterventional observational study HerMES. J Clin Oncol. 2012;30Abstract 4065.

39. Qiu MZ, Li Q, Wang ZQ, et al. HER2-positive patients receiving trastuzumab treatment have a comparable prognosis with HER2-negative advanced gastric cancer patients: a prospective cohort observation. Int J Cancer. 2014;134(10):2468-2477.

40. Jiang J, Wu C, Lu B. Cytokine-induced killer cells promote antitumor immunity. J Transl Med. 2013;11:83.

41. Schmeel LC, Schmeel FC, Coch C, Schmidt-Wolf IG. Cytokine-induced killer (CIK) cells in cancer immunotherapy: report of the international registry on CIK cells (IRCC). J Cancer Res Clin Oncol. 2015;141(5): $839-849$. 
42. Gu X, Gao XS, Cui M, et al. Clinicopathological and prognostic significance of platelet to lymphocyte ratio in patients with gastric cancer. Oncotarget. 2016;7(31):49878-49887.

43. Azab B, Shah N, Radbel J, et al. Pretreatment neutrophil/lymphocyte ratio is superior to platelet/lymphocyte ratio as a predictor of long-term mortality in breast cancer patients. Med Oncol. 2013;30(1):432.

44. Goubran HA, Stakiw J, Radosevic M, Burnouf T. Platelets effects on tumor growth. Semin Oncol. 2014;41(3):359-369.

45. Labelle M, Begum S, Hynes RO. Platelets guide the formation of early metastatic niches. Proc Natl Acad Sci U S A. 2014;111(30): E3053-E3061.

46. Mantovani A, Allavena P, Sica A, Balkwill F. Cancer-related inflammation. Nature. 2008;454(7203):436-444.

47. Rosenberg SA. Progress in human tumour immunology and immunotherapy. Nature. 2001;411(6835):380-384.

48. Bersell K, Arab S, Haring B, Kühn B. Neuregulin1/ErbB4 signaling induces cardiomyocyte proliferation and repair of heart injury. Cell. 2009;138(2):257-270.

49. Gordon LI, Burke MA, Singh AT, et al. Blockade of the erbB2 receptor induces cardiomyocyte death through mitochondrial and reactive oxygen species-dependent pathways. J Biol Chem. 2009;284(4):2080-2087.

50. Zeglinski M, Ludke A, Jassal DS, et al. Trastuzumab-induced health and disease. Physiol Rev. 2007;87:315-424.
51. Riccio G, Coppola C, Piscopo G, et al. Trastuzumab and target-therapy side effects: Is still valid to differentiate anthracycline Type I from Type II cardiomyopathies? Hum Vaccin Immunother. 2016;12(5): 1124-1131.

52. Suter TM, Procter M, van Veldhuisen DJ, et al. Trastuzumab-associated cardiac adverse effects in the herceptin adjuvant trial. J Clin Oncol. 2007;25(25):3859-3865.

53. Pivot X, Suter T, Nabholtz JM, et al. Cardiac toxicity events in the PHARE trial, an adjuvant trastuzumab randomised phase III study. Eur J Cancer. 2015;51(13):1660-1666.

54. Florido R, Smith KL, Cuomo KK, Russell SD. Cardiotoxicity From Human Epidermal Growth Factor Receptor-2 (HER2) Targeted Therapies. J Am Heart Assoc. 2017;6(9):e006915.

55. Swain SM, Baselga J, Kim SB, et al. Pertuzumab, trastuzumab, and docetaxel in HER2-positive metastatic breast cancer. $N$ Engl J Med. 2015;372(8):724-734.

56. Singh R, Kim WJ, Kim PH, Hong HJ. Combined blockade of HER2 and VEGF exerts greater growth inhibition of HER2-overexpressing gastric cancer xenografts than individual blockade. Exp Mol Med. 2013;45(11):e52.

57. Tran PN, Sarkissian S, Chao J, Klempner SJ. PD-1 and PD-L1 as emerging therapeutic targets in gastric cancer: current evidence. Gastrointest Cancer. 2017;7:1-11.
OncoTargets and Therapy

\section{Publish your work in this journal}

OncoTargets and Therapy is an international, peer-reviewed, open access journal focusing on the pathological basis of all cancers, potential targets for therapy and treatment protocols employed to improve the management of cancer patients. The journal also focuses on the impact of management programs and new therapeutic agents and protocols on

\section{Dovepress}

patient perspectives such as quality of life, adherence and satisfaction. The manuscript management system is completely online and includes a very quick and fair peer-review system, which is all easy to use. Visit http://www.dovepress.com/testimonials.php to read real quotes from published authors. 